\title{
Pensión especial de invalidez y prestación humanitaria periódica para víctimas del conflicto armado en Colombia
}

\author{
Special disability pension and periodic humanitarian provision for \\ victims of the armed conflict in Colombia
}

Abogada. Americas Business Process Services S.A. Bogotá, Colombia. Correo electrónico:

dianahuertas89@hotmail.com

Luis Milciades Pérez González.

Economista y Magíster en Gobierno. Defensoría del Pueblo. Bogotá, Colombia Correo electrónico:

Lmperezg@yahoo.com

\begin{abstract}
- $\quad$ Las opiniones expresadas en este artículo no comprometen a la entidad para la que laboran los autores.
Fecha de recepción: 18 de julio de 2016

Fecha de aprobación: 9 de abril de 2017

Cómo citar este artículo/ to reference this article

Huertas Mendivelso, D., \& Pérez González, L. (2017). Pensión especial de invalidez y prestación humanitaria periódica para víctimas del conflicto armado en Colombia. Derecho Y Realidad, 15(29): e9086. Recuperado de https://revistas.uptc.edu.co/index.php/derecho realidad/article/view/9086
\end{abstract}

Resumen: en este artículo se indaga sobre la promulgación de políticas públicas, normas y acciones realizadas para garantizar los derechos de las víctimas del conflicto armado interno afectadas en su integridad personal, en particular lo que en su momento (1997) se llamó pensión especial de invalidez para víctimas de la violencia (PEI) y que a partir de 2017 se modificó a prestación humanitaria periódica para víctimas del conflicto armado (PHP), en el lapso de los últimos veinte años (1997-2017). La investigación se enfoca específicamente en este tipo de víctimas y lo que hasta ahora ha ocurrido con ellas en materia de reparación a través de la PEI o PHP. Los hallazgos obtenidos permiten dimensionar la magnitud del problema que enfrenta esta población en su condición particular de víctimas del conflicto armado. También permite servir de evidencia para que las entidades responsables de garantizar los derechos de esta población cuenten con soportes que optimicen su gestión. Los resultados de esta investigación son útiles para que las víctimas tengan una mayor claridad de su situación y la manera como pueden demandar el cumplimiento de sus derechos. Asimismo, demostrar la grave omisión o fallas del Estado en este tipo de casos. Un tercer impacto de los resultados de esta investigación es la posible contribución en información y evidencia frente al desafío de la implementación de los acuerdos de paz entre el Gobierno nacional y las FARC, en materia de reparación de sus víctimas.

Pensión especial de invalidez y prestación humanitaria periódica para víctimas del conflicto armado en Colombia - Huertas Mendivelso, D., \& Pérez González, L. 
Palabras clave: víctimas de la violencia, revictimización, derechos humanos, prestación humanitaria, seguridad social.

\begin{abstract}
The investigation inquire into the promulgation of public policies, norms and actions carried out to guarantee the rights of the victims of the internal armed conflict affected in their personal integrity, in particular what at the time (1997) was called Special Disability Pension for Victims of Violence (PEI) and that as of 2017 was modified to Periodic Humanitarian Benefit for Victims of Armed Conflict (PHP), in the span of the last twenty years (1997-2017). The research focuses specifically on this type of victims and what has happened so far with them in terms of repair through the PEI or PHP. The findings obtained allow us to measure the magnitude of the problem faced by this population in its particular condition as victims of the armed conflict. It also serves as evidence that the entities responsible for guaranteeing the rights of this population have support that optimizes their management. The results of this investigation are useful for victims to have greater clarity of their situation and how they can demand the fulfillment of their rights. Also, they demonstrate the serious omission or failures of the State in these types of cases. A third impact of the results of this investigation is the possible contribution in information and evidence to the challenge of the implementation of peace agreements between the national government and the FARC, in terms of reparation for their victims.
\end{abstract}

Keywords: victims of violence, double victimization, human rights, humanitarian provision, social security. 


\section{Introducción}

Una de las categorías de análisis en esta investigación es la definición de guerra ${ }^{1}$, particularmente del denominado conflicto armado colombiano ${ }^{2}$. La importancia de esta categoría radica en el impacto que genera en la población, que al ser afectada se convierte en víctima. A partir de las definiciones de Verri (1999) y Waldmann (2007), se puede afirmar que en Colombia existe un conflicto armado que ha generado un alto impacto en daños y víctimas, justificado en propósitos ideológicos y políticos tanto de los grupos guerrilleros que han desafiado al Estado, como de los que se les oponen con las conocidas acciones "contrainsurgentes".

La otra categoría de análisis para considerar es la normatividad humanitaria sobre la guerra (derecho internacional humanitario -DIH-) y los derechos humanos. Dado que los actores armados del conflicto colombiano, en la medida en que no respetaron el DIH, generaron graves y flagrantes violaciones de los derechos humanos e infracciones del derecho internacional humanitario. Entre las conductas reguladas por el DIH en el marco de un conflicto armado no internacional, se encuentran los actos de terrorismo ${ }^{3}$, la instalación de artefactos explosivos improvisados y de minas antipersonal.

La violencia derivada del conflicto armado trajo consigo una gran cantidad de personas afectadas en sus derechos fundamentales y patrimoniales. Unos más que otros. Todas las modalidades y prácticas de violencia, sufridas por miles de personas en Colombia, provocaron daños e impactos que afectaron la integridad de muchas personas, las cuales son consideradas víctimas.

En Colombia, a partir de la expedición de la Ley 1448 de 2011, se reconoce como víctima del conflicto armado la persona que ha sufrido menoscabo de sus derechos a partir de 1985, como consecuencia de infracciones al derecho internacional humanitario o de violaciones graves a las normas internacionales de derechos humanos, ocurridas con ocasión del conflicto armado. También se consideran víctimas a los familiares en primer grado de

\footnotetext{
${ }^{1}$ Se acostumbra a dividir las guerras en internacionales y nacionales, reconociéndose las últimas por pertenecer los bandos a un mismo Estado cuyo territorio representa el escenario bélico. [...] con todo, siempre se alude o refiere al especial ensañamiento y dureza que las distingue (Waldmann, 2007, p. 33).

${ }^{2}$ Verri (1999) define el conflicto armado no internacional (CANI) como sinónimo de "guerra civil": El CANI se caracteriza por el enfrentamiento de las fuerzas armadas de un Estado y fuerzas armadas disidentes o rebeldes. El derecho aplicable durante tales conflictos ha sido considerado durante mucho tiempo como una cuestión de los Estados puramente interna. [...] En el artículo primero del Protocolo II de 1977, se considera conflicto armado no internacional todo conflicto que se desarrolle en el territorio de un Estado, entre sus fuerzas armadas y fuerzas armadas disidentes o grupos armados organizados que, bajo la dirección de un bando responsable, ejerzan sobre una parte de dicho territorio un control tal que les permita realizar operaciones militares sostenidas y concertadas y aplicar el derecho internacional establecido para ese tipo de conflicto (Verri, 1999, p. 26).

3 "Todo ataque indiscriminado perpetrado con explosivos contra objetivos civiles en lugares públicos, con el fin de ocasionar una alta letalidad y devastación sobre la población civil. Se trata de ataques que pretenden asegurar una visibilidad pública de la violencia que contribuya a generar pánico entre la ciudadanía y a propagar una percepción de desestabilización” (Grupo de Memoria Histórica, 2013, p.101).
}

Pensión especial de invalidez y prestación humanitaria periódica para víctimas del conflicto 
consanguinidad y a los cónyuges de los afectados. Acumulativamente, los registros del Estado superaban en más de ocho millones de víctimas hasta el mes de agosto de 2017.

El proceso de atención de las víctimas del conflicto armado interno ha sido traumático y muchas veces revictimizante ${ }^{4}$. A pesar de que la Corte Constitucional declaró el estado de cosas inconstitucional (sentencia T-025 de 2004) en cuanto a la atención de las víctimas por desplazamiento forzado, y reiteró en sendos autos la omisión flagrante de los derechos de las víctimas por parte de las entidades responsables de garantizar su reparación y protección de derechos, ha habido pocos avances en la superación del problema en los últimos años.

En consecuencia, el conflicto armado, además de generar graves violaciones a los derechos humanos e infracciones al derecho internacional humanitario, heredó a los colombianos un problema igual o más grave que las violaciones de derechos humanos, como es el referido a la atención, la reparación y las garantías de no repetición de las víctimas ${ }^{5}$. Luego de casi siete años de aplicación de la Ley 1448 de 2011, aún se encuentran personas víctimas sin registrar en la Unidad para la Atención y Reparación Integral a las Víctimas (UARIV). Y otras aún esperan ser reparadas. Parece una dinámica sin fin. Resulta pertinente entonces dimensionar la gestión que el Estado en su conjunto ha venido realizando para reparar a las

${ }^{4}$ Otros autores hablan de la "victimización secundaria para hacer referencia a la revictimización. En este
sentido, esta se deriva de las relaciones de la víctima con las instituciones sociales de servicios sociales,
sanitarios, medios de comunicación, jurídicos, entre otros (Soria, 2006). Sin embargo, en este caso aplicaría la
definición de revictimización al tener en cuenta que si una persona ha sido víctima y posteriormente es
maltratada por alguna institución porque se le niega información, no se le reconoce como una interlocutora
válida, no se le escucha con el debido respeto y en otros casos estas mismas instituciones a las que acude
porque cumplen alguna función de protección, son las que la amenazan, la investigan, la persiguen. En estos
casos claramente se están evidenciando nuevos episodios de violación de derechos y por lo tanto de
revictimización". Para una mayor ampliación teórica sobre este concepto, véase,
https://www.justiciaypazcolombia.com/los-efectos-psicosociales-de-la-revictimizacion/. El concepto de revictimización se deriva de las quejas generalizadas que las víctimas expresan acerca de la precaria atención recibida de las agencias del Estado. El Grupo de Memoria Histórica (2013) identificó que de "Las personas que han mencionado que recibieron ayudas consistentes, por lo general, en asistencia humanitaria, que no les permitía ningún tipo de estabilidad ni proyección económica y sí los sometía a dispendiosos trámites y los ponía en una situación de permanente dependencia. Algunos mencionaron haber recibido indemnizaciones económicas, con las cuales intentaron reiniciar o montar pequeños negocios. Sin embargo, denunciaron y lamentaron que estas no estuvieran acompañadas de acciones de justicia y verdad, o de un acompañamiento psicosocial que les permitiera manejar los sentimientos ambiguos ocasionados por la culpa, ya que el dinero y las ayudas humanitarias eran percibidos como una especie de soborno" (Grupo de Memoria Histórica, 2013; p.325).

5 "La ausencia de acciones efectivas y consistentes de reparación económica ha contribuido al rápido y progresivo deterioro de la calidad de vida de la mayoría de las víctimas. Las condiciones de miseria y vulnerabilidad provocadas o acentuadas por la guerra las puso en una situación de alta precariedad y riesgo, en la que la subsistencia diaria se convirtió en prioridad. Los dolores y sufrimientos causados por los hechos violentos, en ocasiones parecen "menos relevantes" frente a la angustia diaria por la sobrevivencia y el dolor, la rabia y la frustración provocados por la impotencia de no poder dar a los hijos lo que necesitan. Es importante señalar que las acciones de reparación económica, sin acompañamiento psicosocial y asesorías oportunas sobre el uso del dinero, también han implicado en varios casos la inviabilidad de proyectos productivos e inversiones fracasadas, que generan sensaciones de frustración y culpa en las familias, los grupos y las comunidades. Las víctimas se encontraron ante la ausencia de instituciones de atención idóneas o ante la cooptación de parte de estas por organizaciones criminales. Esto ha fomentado en ellas la percepción de no tener un lugar seguro y confiable dónde acudir y una falta de fe general en las entidades del Estado y en los funcionarios públicos" (Grupo de Memoria Histórica, 2013, p.325). 
víctimas, particularmente las afectadas en su integridad física por atentados terroristas, artefactos explosivos improvisados y por minas antipersonal.

La última categoría de análisis corresponde a la seguridad social, la cual representa un elemento fundamental en la satisfacción de necesidades básicas de los seres humanos y tiene un sustento colectivo en el principio de la solidaridad. En efecto, se trata de un derecho social fundamental que implica un medio para la garantía de otro tipo de derechos. La seguridad social es un instrumento que satisface las necesidades humanas y surge de la capacidad de previsión del individuo y de la solidaridad como valor colectivo. Emerge en la concepción del Estado de bienestar y se constituye como un elemento irrenunciable, al que todo sujeto tiene derecho (Arenas, 2007, citado por Carrillo, 2016, pp. 22-23).

En la Ley 100 de 1993 (Congreso de la República, 1993) se describe que el sistema de seguridad social tiene como fin "garantizar los derechos irrenunciables de la persona y la comunidad para obtener la calidad de vida acorde con la dignidad humana, mediante la protección de las contingencias que la afecten". La seguridad social, desde la jurisprudencia colombiana, es además un derecho que "en principio no ostenta el rango de fundamental, salvo que las circunstancias concretas permitan atribuirse ésta connotación por su importancia imprescindible para la vigencia de otros derechos fundamentales" (Corte Constitucional, 1992, agosto 13), es decir, por conexidad con otro tipo de derechos fundamentales (p. 29).

Uno de los derechos que integra la seguridad social en Colombia, es el de la pensión. Una pensión corresponde a un monto de dinero que se le otorga de manera periódica a una persona en el momento de finalizar su actividad laboral, pues se considera que su etapa productiva ha terminado. Significa que la persona, por su edad o incapacidad para trabajar, recibirá en contraprestación una cantidad de dinero como una forma de contingencia para garantizar su calidad de vida. Por tanto, una pensión es una garantía que favorece a una persona por el esfuerzo realizado en materia laboral durante toda su vida a fin de permitirle gozar una vida digna. Se traduce en una protección hacia el trabajador para que en diferentes situaciones o contingencias puedan seguir gozando del mínimo vital (Carrillo, 2016, p.28).

En consecuencia, la indagación del problema de investigación integra dos grandes temas: en primer lugar, los derechos humanos y el derecho internacional humanitario aplicado en el conflicto armado, y, en segundo lugar, los derechos sociales integrados en el derecho a la seguridad social, específicamente las pensiones. La conjugación de los dos temas en los derechos de las víctimas del conflicto armado, es el interés de los investigadores, que consideran que la pensión (bien sea como PEI o como PHP) contribuiría grandemente a mitigar uno de los principales problemas que las afectan, la falta de ingresos para subsistir a los avatares de la vida diaria.

\section{Metodología}

Se basa en un enfoque jurídico-político, específicamente en la línea de derechos humanos de víctimas. Se llevó a cabo un trabajo de tipo descriptivo y evaluativo. Se aplicó el método

Pensión especial de invalidez y prestación humanitaria periódica para víctimas del conflicto armado en Colombia - Huertas Mendivelso, D., \& Pérez González, L. 
de análisis de huellas ${ }^{6}$, que involucra una estrategia mixta (cualitativa-cuantitativa) de recolección de la información para comprender el problema planteado. Demandó la utilización de una técnica de análisis de contenido que implicó una pesquisa de bibliografía y normatividad sobre el tema, reseñas de autores y fuentes. Para el análisis e interpretación de resultados, la información registrada en la Red Nacional de Información (RNI) de la UARIV fue contrastada con los registros que aportaron Colpensiones y Mintrabajo. La información secundaria se obtuvo de la revisión normativa existente que reglamenta los derechos de la población víctima de la violencia.

En el aspecto cuantitativo, se utilizó información primaria y secundaria relacionada con el problema de investigación. La información primaria se obtuvo de solicitudes (vía derechos de petición) que se hicieron a las diferentes entidades concernidas en la atención de los derechos de la población víctima del conflicto armado. Las entidades concernidas en este problema de investigación corresponden a Colpensiones, la Defensoría del Pueblo, Ministerio de Trabajo y la UARIV. Se construyó una base de datos en Excel de las víctimas a partir de los registros de la RNI.

De los registros estadísticos de la RNI de la UARIV se partió para considerar todas las víctimas de la violencia que han sido afectadas en su integridad personal y cuyas lesiones les hayan ocasionado una pérdida de su capacidad laboral que les impide participar en el mercado laboral formal. Según los registros de la RNI de la UARIV, se estima en unas 13.600 personas víctimas en condición de discapacidad (hasta agosto de 2017). Sin embargo, no todas son candidatas a ser beneficiarias de la pensión especial de invalidez o prestación humanitaria. Los registros estadísticos de la población víctima se contrastó con los registros que Colpensiones y la Defensoría del Pueblo tienen sobre personas que han sido beneficiadas por este derecho. En este sentido, la muestra poblacional seleccionada se reduce a los casos identificados como potenciales beneficiarios de la normatividad existente sobre pensión especial de invalidez para víctimas de la violencia y que han sido fallados por las entidades concernidas para tal fin. También fue necesario restar los miembros de las Fuerzas Armadas y de la Policía Nacional.

El análisis de los registros permitió examinar los casos existentes, los beneficiados y los dejados de atender. Cada uno de los casos fue revisado a la luz de la normatividad vigente, permitiendo evidenciar los principales fallos y barreras que existen en la ruta de atención, reconocimiento y garantía de los derechos humanos de las víctimas de la violencia del conflicto armado interno.

La información secundaria se obtuvo de la revisión normativa existente que reglamenta los derechos de la población víctima de la violencia. Adicionalmente, de la producción bibliográfica relacionada con el problema de investigación.

\section{Hipótesis de investigación}

\footnotetext{
${ }^{6}$ Análisis de huellas: método de investigación que consiste en establecer relaciones entre un fenómeno y sus determinantes mediante el examen de las huellas dejadas por las actividades de los seres humanos (Giroux \& Tremblay, 2004, pp. 98, 101-104, 124 y 195).
} 
La hipótesis que guía esta investigación considera que el Estado colombiano tiene una deuda pendiente con gran cantidad de víctimas del conflicto armado que han sido afectadas en su integridad física y mental, impidiéndoles participar en el mercado laboral formal. Es posible afirmar que en Colombia ser afectado por la violencia del conflicto armado en materia de la integridad personal que le impida trabajar, es una vía segura hacia la pobreza extrema y la indigencia. Intentar obtener la reparación a través de una pensión de invalidez o prestación económica humanitaria es una odisea para quien la emprende y sus resultados son inciertos y costosos.

Se considera que a pesar de las normas promulgadas para su reparación desde hace veinte años, el Estado ha cumplido parcialmente en materia de reparación de las víctimas, enfocando sus programas hacia la población desplazada y especialmente en atención humanitaria de emergencia e indemnización económica; también la inclusión en los programas de subsidios de lucha contra la pobreza extrema.

El Estado ha estado determinado por una marcada lentitud, por el impulso de exigencia de derechos que los ciudadanos han interpuesto ante los jueces a través de los mecanismos como la tutela. Dicha gestión puede estar sustentada también en la consideración de priorizar el equilibrio fiscal antes que la satisfacción de los derechos de las víctimas del conflicto armado, a la verdad, justicia y reparación.

\section{El problema de las víctimas}

La violencia derivada del conflicto armado trajo como resultado una gran cantidad de personas afectadas en sus derechos fundamentales y patrimoniales. Acumulativamente registran un poco más de ocho millones de víctimas. En la Tabla 1 se puede observar el registro que ha hecho la Red Nacional de Información de la Unidad para Atención y Registro Integral de Víctimas del Conflicto Armado Colombiano, conocida como UARIV. Como se ilustra, el total de personas que ostentan la condición de víctimas corresponde a 8.208.564 personas de un total de 9.922 .886 eventos $^{7}$.

Tabla 1. Registro de víctimas del conflicto armado colombiano (personas y eventos)

\footnotetext{
${ }^{7}$ Según la UARIV, las "Personas", corresponden a las "víctimas identificadas de manera única ya sea por su número de identificación, por su nombre completo o por una combinación de ellos". Mientras que "Eventos" corresponde a la "ocurrencia de un hecho victimizante a una persona, en un lugar (municipio) y en una fecha determinada".
}

Pensión especial de invalidez y prestación humanitaria periódica para víctimas del conflicto 


\begin{tabular}{|l|r|}
\hline \multicolumn{1}{|c|}{ HECHO } & PERSONAS \\
\hline Abandono o Despojo Forzado de Tierras & 5.432 \\
\hline Acto terrorista/Atentados/Combates/ Hostigamientos & 96.278 \\
\hline Amenaza & 363.374 \\
\hline Delitos contra la libertad y la integridad sexual & 22.915 \\
\hline Desaparición forzada* & 167.809 \\
\hline Desplazamiento & 7.265 .072 \\
\hline Homicidio** & 990.410 \\
\hline Minas antipersonal/Munición sin explotar/Artefacto explosivo & 11.140 \\
\hline Perdida de Bienes Muebles o Inmuebles & 111.656 \\
\hline Secuestro*** & 36.162 \\
\hline Sin información & 81 \\
\hline Tortura & 10.639 \\
\hline Vinculación de Niños Niñas y Adolescentes & 8.382 \\
\hline
\end{tabular}

Fuente: UARIV 2017. http://rni.unidadvictimas.gov.co/RUV Recuperado 22 de agosto de 2017.

Como se observa, el mayor número de víctimas corresponde al desplazamiento forzado con aproximadamente el $80 \%$ de las víctimas; le siguen los homicidios con un $11 \%$. El restante $9 \%$ se lo distribuyen las demás conductas con un promedio entre el 1 y $2 \%$, respectivamente.

Para los objetivos de este análisis, la población de víctimas objeto de estudio corresponde a las víctimas que sufrieron ataques contra su integridad personal y quedaron gravemente afectadas en su condición física, lo que les impide trabajar, o que en todo caso su capacidad laboral fue afectada en más del $50 \%$. En ese sentido, los hechos victimizantes por considerar corresponden a las minas antipersonal, los artefactos explosivos improvisados, actos de terrorismo, tortura, entre los más determinantes. De estas conductas, los accidentes e incidentes por minas antipersonal (en adelante MAP), son los mayores generadores de víctimas que terminan en condición de discapacidad.

De acuerdo con la Tabla 1, a la fecha la RNI-UARIV registra 11.140 víctimas que dejan las minas antipersonal, municiones sin explotar y demás artefactos explosivos. A este registro habría que sumarle las víctimas de actos terroristas y atentados. En su conjunto, la UARIV registra un total de 214.960 personas víctimas del conflicto que actualmente se encuentran en condición de discapacidad (Tabla 2). Sin embargo, es necesario aclarar que no es posible determinar con exactitud si todas las víctimas en condición de discapacidad lo estaban antes de ser victimizadas por el conflicto o lo fueron por causa del mismo. Tampoco es posible saber el grado de afectación de su discapacidad que les impida trabajar y en su defecto, acceder a la reparación vía pensión de invalidez para víctimas de la violencia.

Tabla 2. Discapacidad de personas víctimas del conflicto 


\begin{tabular}{|l|r|}
\hline Con discapacidad & 214.960 \\
\hline Sin discapacidad & 7.993 .604 \\
\hline Total de víctimas & 8.208 .564 \\
\hline
\end{tabular}

Fuente: UARIV http://rni.unidadvictimas.gov.co/RUV (agosto 2017)

\subsection{Marco jurídico internacional y nacional frente a la protección de los derechos fundamentales de las víctimas del conflicto $\operatorname{armado}^{8}$}

Para poder entender la evolución de la normatividad en Colombia para garantizar los derechos de la población víctima de la violencia del conflicto armado, se debe recordar que en los años noventa se desató una violencia terrorista que obligó al Estado a reforzar medidas que consideraran en primer lugar la atención y ayuda a las personas afectadas por los actos terroristas o por la violencia desatada por las organizaciones armadas ilegales. Lo anterior llevó a que las víctimas del conflicto armado y de la violencia sociopolítica ganaran atención en las últimas dos décadas. Esto se refleja en el importante proceso legislativo expresado en las siguientes leyes: Ley 104 de 1993, Ley 241 de 1995, Ley 418 de 1997, Ley 387 de 1997, Ley 782 de 2002, Ley 975 de 2005 y la Ley 1106 de 2006. Normas que tuvieron distintos alcances y procesos de aplicación en beneficio de las víctimas y poblaciones afectadas por la guerra.

Se expidió la Ley 104 de 1993, artículo 45, inciso 2 que establece que: "Las víctimas de los atentados que sufrieren una disminución de su capacidad física desde un $66 \%$ calificada por el Fondo de Solidaridad Pensional, tendrán derecho a una pensión mínima legal vigente siempre y cuando carezca de otras posibilidades pensionales y de atención en salud". Esta ley por primera vez intenta dar protección a las víctimas de la violencia, aunque estableciendo como requisito una pérdida de capacidad laboral muy alta.

Al hacerse evidente la falencia y disconformidad con el requisito de pérdida de capacidad laboral tan elevado, se creó la Ley 241 de 1995, la cual en su artículo 15 modificó el inciso 2 del artículo 45 de la Ley 104 de 1993, quedando así: "Las víctimas que sufrieron una pérdida del $50 \%$ o más de su capacidad laboral calificada con base en el Manual Único para la Calificación de Invalidez expedido por el Gobierno Nacional, tendrán derecho a una pensión mínima legal vigente, de acuerdo con lo contemplado en el Régimen General de Pensiones de la Ley 100 de 1993, siempre y cuando carezcan de otras posibilidades

\footnotetext{
${ }^{8}$ Esta investigación se enfoca en la revisión de leyes, decretos y resoluciones que tienen en materia de garantía de los derechos de las personas con PCL superior al $50 \%$ para tener derecho a la pensión especial de invalidez como víctimas de la violencia. Se exceptúan de este análisis los integrantes de las Fuerzas Armadas y Policía Nacional, los cuales son actores del conflicto armado, toda vez que actúan en nombre, representación y defensa del Estado. Además, cuentan con un régimen pensional especial, reglamentado en la Ley 923 del 30 de diciembre de 2004.
}

Pensión especial de invalidez y prestación humanitaria periódica para víctimas del conflicto armado en Colombia - Huertas Mendivelso, D., \& Pérez González, L. 
pensionales y de atención en salud”. Sin embargo, este artículo también fue modificado, a fin de ampliar y especificar la protección del Estado.

La Ley 418 de 1997 contiene disposiciones para proteger a los civiles contra los efectos del conflicto armado, la atención y asistencia a las víctimas de hechos violentos que se susciten en el marco del conflicto armado interno. Esta Ley, en su artículo 131, derogó las leyes 104 de 1993 y 241 de 1995. Asimismo, en el artículo 46, inciso 2 señaló que "Las víctimas que sufrieren una pérdida del $50 \%$ o más de su capacidad laboral calificada con base en el Manual Único para la calificación de invalidez expedido por el Gobierno Nacional, tendrán derecho a una pensión mínima legal vigente, de acuerdo con lo contemplado en el Régimen General de Pensiones de la Ley 100 de 1993, siempre y cuando carezcan de otras posibilidades pensionales y de atención en salud, la que será cubierta por el Fondo de Solidaridad Pensional a que se refiere el Artículo 25 de la Ley 100 de 1993”. Con la creación de esta ley se buscaba cobijar la situación de las víctimas de la violencia, las cuales tenían una doble condición de vulnerabilidad, las de ser víctimas del conflicto armado y estar en estado de discapacidad.

Con la promulgación de la Ley 387 de (1997), se brindan elementos para aproximarse al concepto de víctima del conflicto armado, estableciendo un modelo de intervención basado fundamentalmente en la asistencia. En este sentido, la Ley 387 establece que a esta población debe brindársele condiciones para mejorar su situación a nivel individual y familiar, bien sea a través de su retorno o reubicación, sin que implique desarrollar acciones estructurales que transformen sus circunstancias. Estas normas configuran, para ese momento (leyes 387 y 418 de 1997), la estructura central del tratamiento a las víctimas de la confrontación armada.

La Ley 975 de 2005 reglamentó los mecanismos de sometimiento y reincorporación individual o colectiva a la vida civil de miembros de grupos armados al margen de la ley, garantizando los derechos de las víctimas a la verdad, la justicia y la reparación. Esta norma desarrolla los conceptos de víctima, reparación, verdad, justicia, así como los requisitos para la desmovilización individual y colectiva. En desarrollo de esta norma, se expidió el Decreto 1290 de 2008, que estableció lo relacionado con el Programa de Reparación Individual por vía Administrativa y la Indemnización.

Como lo señaló en su momento la Fundación Ideas para la Paz (2007), el proceso de reparación puso en evidencia tres problemas principales:

1. El elevado número de víctimas reclamantes.

2. Los problemas de seguridad de las víctimas y testigos, de quienes dependía el éxito de las investigaciones contra los paramilitares.

3. El elevado costo económico que implicaba la indemnización por parte del Estado a las víctimas.

En todo caso, como puede observarse hoy en día, ninguna de estas vías resultó plenamente satisfactoria para las víctimas. Se cayó en la improvisación al desarrollar estas políticas y programas, afectados por las deficiencias propias del Estado. Además se creó un ambiente de frustración en numerosas personas que se hicieron a la idea de que la reparación integral 
ofrecida por el Estado se iba a materializar en cambios sociales, económicos y políticos que iban más allá de lo pecuniario, sumados a un escenario de equidad y proporcionalidad en las reparaciones.

\subsection{La sentencia T-025 de 2004 y la declaración de estado de cosas inconstitucional}

La grave crisis ocasionada por los impactos del conflicto armado, llevaría a la Corte Constitucional a proferir la sentencia T-025 de 2004. Fallo que en lo fundamental se concentra en exigir del Estado el cumplimiento cabal de la ley a través de la adopción de las medidas para superar las circunstancias que, de acuerdo con el alto tribunal, generan la existencia de un estado de cosas inconstitucional.

Motivó esta declaración de la Corte, la constatación de la violación de derechos fundamentales de la población desplazada "de manera masiva, prolongada y reiterada [...] que obedece a un problema estructural que afecta a toda la política de atención diseñada por el Estado, y a sus distintos componentes, en razón a la insuficiencia de recursos destinados a financiar dicha política y a la precaria capacidad institucional para implementarla" (Tutela 025, 2004). Esta evaluación trajo como resultado el hallazgo de una serie de situaciones de grave desconocimiento de los derechos de las víctimas.

Desde el primer momento, la Corte consideró que las víctimas del desplazamiento son una categoría de ciudadanos especiales, sujetos de derechos fundamentales de contenido específico y que además la naturaleza constitucional de sus derechos es de carácter prestacional. En consecuencia, consideró que el Estado colombiano debía generar acciones progresivas para lograr el goce de estos derechos. Este fallo considera que el Estado debe generar acciones progresivas para lograr el goce de estos derechos con una respuesta adecuada.

\subsection{Sistema Nacional de Atención y Reparación Integral a Víctimas del Conflicto Armado (SNARIV)}

\section{Ley 1448 de 2011}

La Ley 1448 de 2011, "por la cual se dictan medidas de atención, asistencia y reparación integral a las víctimas del conflicto armado interno y se dictan otras disposiciones", unificó las normas expedidas hasta ese momento.

Esta norma constituyó un avance indiscutible en el reconocimiento de los derechos y las garantías de las víctimas del conflicto armado y configura hoy en día el principal marco para orientar la acción del Estado en materia de reparación administrativa.

La Ley 1448 de 2011 recoge varios aspectos centrales, dentro de los que se destaca en primer lugar el concepto de víctima, entendida como la persona que ha sufrido menoscabo de sus derechos a partir de 1985, como consecuencia de infracciones al derecho internacional humanitario o de violaciones graves a las normas internacionales de derechos humanos, ocurridas con ocasión del conflicto armado. También se consideran víctimas a 
los familiares en primer grado de consanguinidad y a los cónyuges de los afectados. Se incluye en esta definición a los niños y adolescentes desvinculados de los grupos armados.

La Ley 1448 avanza conceptualmente en precisar las definiciones de asistencia, reparación y restitución, diferenciando las medidas según el tipo de víctimas, y estableciendo unas fases o etapas que parten de la asistencia, entendida como la ayuda que demanda una persona en el momento de sufrir una vulneración, con el objetivo de restablecer derechos fundamentales amenazados, como la salud o la alimentación, la reparación y la restitución, incluyendo allí el concepto de reparación simbólica.

Finalmente, cabe señalar que la Ley 1448 establece las siguientes acciones en materia de reparación integral: restitución de tierras, restitución de vivienda, créditos y pasivos, indemnización por vía administrativa, medidas de rehabilitación, medidas de satisfacción, medidas de prevención, protección y garantías de no repetición.

Se organizó el Sistema Nacional de Atención y Reparación Integral a las Víctimas (SNARIV), que incorpora distintas instituciones del orden nacional y territorial responsables de la adopción de planes, programas, proyectos y medidas en materia de atención y reparación. Se partió del supuesto de que entre estas entidades se iban a lograr avances concretos en aspectos sensibles como la formulación y la implementación de políticas, la apropiación e implementación de mecanismos para facilitar el acceso y la asistencia a las víctimas, la canalización y utilización adecuada de los recursos para atender las distintas dimensiones de la problemática $\mathrm{y}$, por supuesto, una adecuada coordinación interinstitucional soportada en la articulación de los distintos programas, recursos, bienes y servicios.

\section{El Sistema de Seguridad Social en Colombia: la pensión}

Con la Constitución Política de 1991, se abrió el camino para que el Sistema de Seguridad Social se consagrara con rango constitucional como uno de los derechos sociales, económicos y culturales irrenunciables. Para su cumplimiento eficaz le impuso al Estado la carga de ampliar su cobertura, hasta llegar a la universalización.

Se trata de un derecho social fundamental que implica un medio para la garantía de otro tipo de derechos. La seguridad social es un instrumento que satisface las necesidades humanas y surge de la capacidad de previsión del individuo y de la solidaridad como valor colectivo. Emerge de la concepción del Estado de bienestar y se constituye como un elemento irrenunciable, al que todo sujeto tiene derecho (Arenas, 2007, citado por Carrillo 2016, pp. 22-23).

En la Ley 100 de 1993 (Congreso de la República, 1993) se describe que el Sistema de Seguridad Social tiene como fin "garantizar los derechos irrenunciables de la persona y la comunidad para obtener la calidad de vida acorde con la dignidad humana, mediante la protección de las contingencias que la afecten". La seguridad social, según la jurisprudencia colombiana, es además un derecho que "en principio no ostenta el rango de fundamental, salvo que las circunstancias concretas permitan atribuirse ésta connotación por su importancia imprescindible para la vigencia de otros derechos fundamentales" (Corte 
Constitucional, T-491 de agosto 13 de 1992), es decir, por conexidad con otro tipo de derechos fundamentales (citado por Carrillo, 2016; p. 29).

Uno de los derechos que integra la seguridad social en Colombia, es el de la pensión. Una pensión corresponde a un monto de dinero que se le otorga de manera periódica a una persona en el momento de finalizar su actividad laboral, pues se considera que su etapa productiva ha terminado. Significa que la persona, por su edad o incapacidad para trabajar, recibirá en contraprestación una cantidad de dinero como una forma de contingencia para garantizar su calidad de vida. Por tanto, una pensión es una garantía que favorece a una persona por el esfuerzo realizado en materia laboral durante toda su vida a fin de permitirle gozar una vida digna. Se traduce en una protección hacia el trabajador para que en diferentes situaciones o contingencias puedan seguir gozando del mínimo vital (Carrillo, 2016, p.28).

Como derecho social, la pensión es un esquema de rentas o pagos periódicos que una persona se compromete a realizar a otra, a partir del cumplimiento de una condición preestablecida. La causa que genera el pago y su monto son elementos cruciales en la determinación de la pensión, lo mismo que las fuentes de su financiamiento (Merchán, 2002, p.14).

\subsection{La administración del Régimen de Prima Media (RPM)}

Con la sanción de la Ley 100 de 1993, se crearon dos tipos de regímenes pensionales: el Régimen de Ahorro Individual con Solidaridad -RAIS-, administrado por entidades privadas, y el Régimen de Prima Media con Prestación Definida-RPM-, o público, administrado por la Administradora de Pensiones, Colpensiones. A efectos de esta investigación, solo se considera el RPM que administra Colpensiones, como entidad pública y encargada de estudiar, reconocer y administrar las pensiones especiales de invalidez para víctimas de la violencia.

El RPM, bajo la administración de Colpensiones, cubre seis tipos de pensiones: pensión de vejez $^{9}$, pensión de sobreviviente ${ }^{10}$, pensión de invalidez por riesgo de origen común ${ }^{11}$ y las pensiones especiales de vejez ${ }^{12}$, familiar ${ }^{13}$ y de invalidez para víctimas de la violencia $(\mathrm{PEI})^{14}$. Este último tipo de pensión es la de interés para la presente investigación.

\footnotetext{
${ }^{9}$ Prestación económica que se le otorga al afiliado, siempre y cuando cumpla con los requisitos contemplados en la ley.

${ }^{10}$ Prestación económica que deja el afiliado o pensionado después de su fallecimiento. También se debe cumplir con los requisitos de ley.

${ }^{11}$ Prestación económica reconocida por el RPM al afiliado que ha perdido capacidad laboral igual o superior al $50 \%$. Debe cumplir con los requisitos que establece la ley.

${ }^{12}$ Pueden acceder a la pensión de manera anticipada el padre o madre cabeza de familia con hijos inválidos siempre y cuando dependan de él o ella.

13 Se reconoce por la suma de esfuerzos de cotización de cada uno de los cónyuges o compañeros permanentes, deben cumplir los requisitos establecidos por la ley.

${ }^{14}$ Prestación económica que se reconoce a quienes han sido víctimas del conflicto armado interno, que les ha generado incapacidad laboral igual o superior al $50 \%$ y no cuentan con ingreso alguno para solventar sus necesidades económicas y de atención en salud (Ley 418/1997 art. 46). Se debe considerar que a partir de
}

Pensión especial de invalidez y prestación humanitaria periódica para víctimas del conflicto armado en Colombia - Huertas Mendivelso, D., \& Pérez González, L. 


\subsection{La pensión especial de invalidez para las víctimas de la violencia (PEI)}

La PEI fue un mecanismo jurídico diseñado por el Estado colombiano, para reparar integralmente a las víctimas del conflicto armado interno. Como prestación económica, buscaba que las víctimas obtuvieran un ingreso periódico a su favor, para quienes el conflicto armado interno les generó incapacidad laboral igual o superior al $50 \%$ y no cuentan con ingreso alguno para solventar sus necesidades económicas y de atención en salud (Ley 418/1997 art. 46). Además, para acceder a él, no era necesario estar afiliado o haber pertenecido en algún momento al Régimen General de Pensiones.

A pesar de que fue instituido desde 1997 con la Ley 418, hasta 2014 no se tuvo conocimiento de alguna persona que haya sido beneficiada con este derecho pensional. Por el contrario, han sido las entidades responsables de su garantía, las que han intentado que se derogue o se transforme en otro tipo de derecho asistencial de emergencia o que sea pagado por una sola vez. Fue necesario que la Corte Constitucional, mediante la sentencia de tutela T-469 de 2013, resaltara la progresividad de los derechos económicos, sociales y culturales y la consecuente obligación del Estado de mejorar cada día el goce y ejercicio de los mismos. Esta razón es la que mantuvo vigente la prestación económica en favor de esta población objeto de especial protección especial constitucional, hasta el año 2017.

Para entender un poco las vicisitudes normativas por las que ha transcurrido el derecho de las víctimas para acceder a la PEI, obsérvense las siguientes tablas que ilustran su evolución normativa (tablas 3 y 4):

Tabla 3. Marco normativo sobre la PEI

\begin{tabular}{|c|c|}
\hline NORMA & PRECISIÓN \\
\hline $\begin{array}{l}\text { Ley } 104 \text { de } \\
1993 \\
\text { artículo } 45 \\
\text { Inciso } 2^{\circ}\end{array}$ & $\begin{array}{l}\text { Pérdida de capacidad laboral del } 66 \% \text {, no tener ningún ingreso para solventarlas, pago de esta } \\
\text { prestación económica fue asumido por el Fondo de Solidaridad y Emergencia Social de la } \\
\text { Presidencia de la República. }\end{array}$ \\
\hline $\begin{array}{l}\text { Ley } 241 \text { de } \\
\quad 1995 \\
\text { artículo } 15\end{array}$ & $\begin{array}{l}\text { El artículo } 15 \text { de la precitada ley modificó el inciso } 2 \text { del artículo } 45 \text { de la Ley } 104 \text { de } 1993, \\
\text { quedando los requisitos así: pérdida de capacidad laboral del } 50 \% \text {, no contar con ningún otro } \\
\text { ingreso para solventar las consecuencias económicas derivadas por el conflicto armado, pago de } \\
\text { esta prestación económica fue asumido por el Fondo de Solidaridad y Emergencia Social de la } \\
\text { Presidencia de la República. }\end{array}$ \\
\hline $\begin{array}{l}\text { Ley } 418 \text { de } \\
1997 \\
\text { artículo } 46 \\
\text { Inciso } 2^{\circ}\end{array}$ & $\begin{array}{l}\text { El artículo } 131 \text { derogó la Ley } 104 \text { de } 1993 \text {, estableciendo los siguientes requisitos: pérdida de } \\
\text { capacidad laboral del } 50 \% \text {, carecer de otras posibilidades pensionales y de atención en salud, } \\
\text { pago de esta pensión será cubierta por el Fondo de Solidaridad Pensional. }\end{array}$ \\
\hline $\begin{array}{l}\text { Ley } 548 \\
\text { de } 1999\end{array}$ & Prorrogó la vigencia del artículo 46 de la Ley 418 de 1997 por 3 años. \\
\hline $\begin{array}{r}\text { Ley } 782 \\
\text { de } 2002 \\
\end{array}$ & Prorrogó la vigencia del artículo 46 de la Ley 418 de 1997 por 4 años. \\
\hline $\begin{array}{l}\text { Ley } 1106 \\
\text { de } 2006\end{array}$ & Prorrogó la vigencia de la Ley 418 de 1997 pero no se pronunció e \\
\hline
\end{tabular}

abril de 2017, con la promulgación del Decreto 600 de 2017, pasa a ser administrada por el Ministerio de Trabajo y bajo el nombre de prestación humanitaria periódica para víctimas del conflicto armado. 
Ley 1421 Prorrogó la vigencia de la Ley 418 de 1997 pero ni de manera expresa o tácita se de 2010 pronunció frente a la pensión especial de invalidez.

Tabla 4. Línea jurisprudencial, víctimas de la violencia, subsidio económico

\begin{tabular}{|c|c|}
\hline SENTENCIA & DECISIÓN \\
\hline $\begin{array}{c}\mathrm{T}-469 \mathrm{de} \\
2013\end{array}$ & $\begin{array}{l}\text { Ordenó a Colpensiones informar a los ciudadanos víctimas de la violencia que soliciten el } \\
\text { reconocimiento y pago de la pensión especial de invalidez; advirtió a Colpensiones para que en adelante } \\
\text { interprete el alcance y contenido de la pensión por invalidez para víctimas de la violencia; reconoce } \\
\text { que Colpensiones tiene derecho a repetir contra el Fondo de Solidaridad Pensional, a través del } \\
\text { Consorcio Prosperar. }\end{array}$ \\
\hline $\begin{array}{c}C-767 \mathrm{de} \\
2014\end{array}$ & $\begin{array}{l}\text { Fundamento jurídico: advierte una comisión legislativa por cuanto no amplió la vigencia de la } \\
\text { prestación económica reconocida a favor de las víctimas del CAI de la Ley } 418 \text {. Desconocimiento del } \\
\text { principio de no regresividad de los DESC, sin que se acreditaran criterios de razonabilidad, necesidad y } \\
\text { proporcionalidad. Declaró que la prestación económica se encontraba vigente. }\end{array}$ \\
\hline $\begin{array}{l}\mathrm{T}-921 \mathrm{de} \\
2014\end{array}$ & $\begin{array}{l}\text { Para el reconocimiento de las pensiones especiales de invalidez para las víctimas de la violencia deberá } \\
\text { verificarse que el peticionario NO se encuentra afiliado al régimen contributivo en salud. }\end{array}$ \\
\hline $\begin{array}{c}\mathrm{T}-032 \mathrm{de} \\
2015\end{array}$ & $\begin{array}{l}\text { Reconoce que Colpensiones tiene derecho a repetir contra el Fondo de Solidaridad Pensional, a través } \\
\text { del Consorcio Prosperar; ADVERTIR a Colpensiones, para que en adelante interprete el alcance y } \\
\text { contenido de la pensión contemplado en el artículo } 46 \text { de la Ley } 418 \text { de } 1997 \text {, de conformidad con lo } \\
\text { expuesto en la sentencia C- } 767 \text { de } 2014 \text {. }\end{array}$ \\
\hline $\begin{array}{l}\mathrm{T}-074 \mathrm{de} \\
2015\end{array}$ & $\begin{array}{l}\text { Menciona que la pensión a favor de las víctimas de la violencia siguió existiendo con la sentencia C- } \\
767 \text { de } 2014 \text {, existe la certeza de que dicha prestación sigue vigente en el ordenamiento jurídico, señaló } \\
\text { los requisitos para acceder a la pensión. }\end{array}$ \\
\hline $\begin{array}{c}\mathrm{SU}-587 \mathrm{de} \\
2016\end{array}$ & $\begin{array}{l}\text { Esta sentencia proferida por la Corte Constitucional. ORDENA al Ministerio del Trabajo constituir } \\
\text { fiducia con el fin de asegurar un capital que permita cubrir el pago de las pensiones especiales de } \\
\text { invalidez a favor de las víctimas que sean reconocidas por Colpensiones. Fiducia que deberá reembolsar } \\
\text { a Colpensiones la totalidad de las sumas dinero que la citada administradora haya destinado para } \\
\text { garantizar el pago periódico de las pensiones especiales de invalidez que sean reconocidas, y ordena al } \\
\text { Ministerio de Hacienda y Crédito Público desembolsar los recursos del Presupuesto General de Nación } \\
\text { que permitan financiar, la pensión especial de invalidez a favor de las víctimas de la violencia. }\end{array}$ \\
\hline
\end{tabular}

En este mismo sentido, la Defensoría del Pueblo (2015), a través de una acción de tutela que representaba a las víctimas de la violencia, consideraba positivamente la necesidad de reconocer la PEI como una prerrogativa de carácter indemnizatorio a la luz del derecho internacional de los derechos humanos, y la normatividad interna:

Específicamente, tratándose de víctimas con lesiones físicas permanentes o parciales producto del conflicto armado, la ley ha establecido el reconocimiento de una pensión especial de invalidez, aún sin encontrarse afiliado al sistema de seguridad social, con el fin de mitigar la situación de vulnerabilidad de éstas personas, en su mayoría imposibilitadas para generar ingresos que aseguren su optima subsistencia y la de su núcleo familiar. Esta prerrogativa, se constituye como un mecanismo de reparación de carácter indemnizatorio, a la luz del Derecho Internacional de los Derechos Humanos, y la normatividad interna. (Defensoría del Pueblo, 2015, p. 12).

\subsection{Sentencia Unificada 587 de 2016}

Esta sentencia buscó proteger los derechos fundamentales y el derecho a la pensión especial de invalidez del señor José Ferney González Pérez, víctima, por lo mismo procede a levantar la decisión de dejar en suspenso el reconocimiento y pago de la pensión. La orden de la Corte es clara, pero la misma no se ha cumplido por parte del Ministerio de Trabajo, por lo tanto está incurriendo en desacato a la ley. 
Por el contrario, el Ministerio de Trabajo expidió el Decreto 600 de 2017, creando una nueva denominación ahora llamada prestación humanitaria periódica para víctimas del conflicto armado. En este sentido, no continuó con la financiación de la pensión especial de invalidez.

\subsection{Decreto 600 de 6 de abril de 2017 "Prestación Humanitaria Periódica para las Víctimas del Conflicto Armado" (PHP)}

Con el fin de dar aplicación a lo ordenado por la Corte Constitucional, Colpensiones emitió tres conceptos jurídicos, los cuales fueron suspendidos por: 1) no estar definida la competencia para efectuar el pago e inclusión en nómina de la pensión de vejez para víctimas de la violencia; 2) no se tenía certeza cuál entidad la respaldaría presupuestalmente, si el Ministerio de Hacienda o el Ministerio de Trabajo.

La sentencia C-767 (2014) de la Corte Constitucional señala:

[...] cuando la ley no tiene previsto un método de cotización previa, ni requisitos de tiempo de servicio o edad o semanas de cotización para otorgar una subvención, la prestación económica de la cual se trata no puede considerarse en modo alguno una pensión de vejez o invalidez estrictamente hablando pues carece de los requisitos y características propias del régimen de pensiones, debiendo entenderse como un estímulo de otra naturaleza.

Frente al anterior pronunciamiento, el Ministerio de Trabajo presentó solicitud de aclaración ante la Corte Constitucional, la cual respondió lo siguiente: "la prestación económica denominada pensión de invalidez para víctimas del conflicto armado no pertenece al Sistema General de Pensiones y, por tanto, no tiene su origen en la seguridad social" (auto 290, 2015). Con lo anterior queda claro que a la ayuda económica para víctimas de la violencia, que estaba reconociendo la Administradora Colombiana de Pensiones bajo la denominación de pensión especial de invalidez para víctimas de la violencia, no le serían aplicables las reglas del Sistema de Seguridad General en Pensiones.

En este sentido, se podría interpretar que el Estado había cometido un error al considerarla como "pensión especial" en el artículo 46 de la Ley 418 de 1997. Por tanto, era necesario resarcir su error corrigiendo lo que había reglamentado, esto es, que las víctimas del conflicto con una pérdida del $50 \%$ o más de su capacidad laboral con ocasión del conflicto armado, tendrían derecho a una pensión mínima legal vigente. Fue así como, siguiendo los lineamientos de la sentencia de la Corte Constitucional 767 de 2014, tuvo que expedir el Decreto 600 de 6 de abril de 2017, el cual determinó quién es el responsable del reconocimiento, las condiciones de acceso, el procedimiento operativo y la fuente de recursos de la prestación humanitaria periódica para las víctimas del conflicto armado prevista en el artículo 46 de la Ley 418 de 1997.

Algunas características por resaltar del Decreto 600 del 6 de abril de 2017, son las siguientes: 
1) Con la expedición del Decreto 600 de 2017, la prestación económica no continúa llamándose "pensión especial de invalidez para víctimas de la violencia", debido a la carencia de requisitos del régimen de pensiones y a su naturaleza del aporte periódico de dinero, para mantener la racionalidad económica. Pasa a denominarse "prestación humanitaria periódica para las víctimas del conflicto armado", lo cual se encuentra enmarcado dentro de la reparación que otorga al Estado a las víctimas de la violencia. El cambio de denominación, requisitos y origen no beneficia a las víctimas, toda vez que la connotación legal es diferente y resulta más beneficiosa para las víctimas la pensión especial.

2) En cuanto al ámbito de aplicación, corresponde a las víctimas que con posterioridad a la entrada en vigencia de la Ley 418 de 1997 (26 de diciembre de 1997) hubiesen sufrido una pérdida de capacidad laboral igual o superior al $50 \%$ como consecuencia de un acto de violencia suscitado en el marco del conflicto armado interno. Ante la irretroactividad que rige la aplicación de la ley, cabe preguntarse ¿qué ha pasado con todas aquellas personas que sufrieron pérdida de capacidad laboral igual o superior al $50 \%$ antes del 26 de diciembre de 1997? ¿Quedaron en el olvido, o les dieron una ayuda humanitaria temporal o aún peor, una indemnización económica que no alcanza para llevar una vida digna y tener una muerte igual?

3) En cuanto a los requisitos establecidos por el Decreto: no ser beneficiario de subsidio, auxilio, beneficio o subvención económica periódica, ni de otro tipo de ayuda para subsistencia por ser víctima, es necesario tener en cuenta que las personas víctimas del conflicto armado, físicamente impedidas para trabajar, en su mayoría son de origen humilde y en muchas de las ocasiones eran las que llevaban el sustento al hogar. Por lo tanto resulta poco protector al no permitir que en el momento de la solicitud de reconocimiento de la prestación humanitaria periódica, estén recibiendo ayuda o subsidio materializado en dinero por parte de una misma entidad gubernamental o por cooperación internacional; asimismo, el cumplimiento de este requisito es ambiguo, toda vez que no establece si el valor de lo recibido es inferior, igual o superior a un salario mínimo mensual legal vigente.

4) En cuanto a la financiación y pago de la prestación humanitaria periódica, quedó estipulado que los recursos que se requieran para el pago de la prestación provendrán del Presupuesto General de la Nación. Para el efecto, el Ministerio de Hacienda y Crédito Público apropiará anualmente del presupuesto del Ministerio del Trabajo y este, a su vez, deberá realizar todas las actuaciones administrativas y presupuestales que correspondan para garantizar el pago de dicha prestación. Uno de los principales inconvenientes que enfrentó Colpensiones para el reconocimiento y pago de la "pensión especial de invalidez para víctimas de la violencia", era la de no tener certeza cuál Ministerio (Hacienda o Trabajo) la respaldaba presupuestalmente. Esta situación generó que Colpensiones, al efectuar el posterior recobro al Consorcio Colombia Mayor, administrado por el Ministerio de Trabajo, resultó en controversia entre las dos entidades, debido a la negativa sostenida y permanente del Fondo de Solidaridad de acceder a los recobros. 
5) En cuanto a las obligaciones del Ministerio de Trabajo, particularmente la que indica que cada tres años se debe efectuar calificación de pérdida de capacidad laboral de las víctimas, para ratificar, modificar o dejar sin efectos el dictamen que sirvió de fundamento para obtener el reconocimiento de la prestación humanitaria periódica y proceder a la extinción de la prestación humanitaria periódica, si a ello hubiere lugar; cuando la prestación económica era llamada "pensión especial de invalidez para víctimas de la violencia", Colpensiones conceptuó que debía realizarse valoración cada tres años, lo que no se efectuó, el reconocimiento era vitalicio. Pero, con el nuevo decreto y su reglamentación, cada tres años tienen que practicarse nuevamente el examen que determine la pérdida de capacidad laboral y además con sus propios recursos, para verificar si la misma se mantiene o si en efecto el dictamen disminuye la pérdida de capacidad inferior al $50 \%$, lo cual quiere decir que la víctima se puede recuperar ${ }^{15}$, puede retomar sus labores y una vida "normal”. De ser así, será suspendida la prestación humanitaria.

6) En cuanto a la pérdida de la prestación humanitaria periódica, señala que con la muerte del beneficiario se cierra toda posibilidad de transferir a su cónyuge sobreviviente o hijos inválidos, como lo es la pensión de sobreviviente. Para aminorar el dolor por la pérdida del ser amado y tener un sustento mensual mínimo para sobrevivir, el Estado debería ser más amplio en cuanto a protección de derechos y conceder la prestación humanitaria periódica para las víctimas del conflicto armado a los sobrevivientes, siempre y cuando reúnan los requisitos que se establezcan por ley.

7) En cuanto a la presentación de solicitud para calificación de pérdida de capacidad laboral, estableció que las víctimas deben acudir directamente a la Junta Regional de Calificación de Invalidez, la cual, a su vez, actúa como perito del Estado, para demostrar el interés jurídico y la historia clínica que reflejen los hechos de la fecha en que ocurrió el acto de violencia que causó la invalidez. Si bien es cierto que el Decreto establece a dónde se deben dirigir las víctimas para la calificación de pérdida de capacidad laboral, no tiene en cuenta que no hay Juntas Regionales de Calificación en todos los departamentos, sino que en el ámbito nacional solo existen 17 Juntas Regionales de Calificación de Invalidez (Ministerio del Trabajo, 2016). En lo relacionado con el pago del dictamen, se establece que las víctimas del conflicto que soliciten dictamen de pérdida de capacidad laboral, pagarían a la Junta Regional correspondiente, el equivalente a un salario mínimo legal mensual vigente por cada dictamen solicitado, de conformidad con el artículo 2.2.5.1.16 del Decreto 1072 de 2015.

Como si no fuera suficiente con la condición de pérdida igual o superior al $50 \%$ de capacidad laboral y de haber sido víctimas del conflicto armado, a las víctimas les toca con

\footnotetext{
${ }^{15}$ Parece un cinismo la exigencia de este requisito, como si los órganos mutilados (piernas, brazos, dedos, ojos, oídos, etc.) por el acto violento volvieran a restaurarse después de un tiempo. Esta situación revictimiza a las personas que sufrieron tales lesiones, pues cada tres años deben revivir el trauma y además financiarlos con sus propios recursos. Según el Consejo de Estado, M.P. Rojas (Sentencia 2000-00340 del 28 de Agosto de 2014), estamos frente a un daño moral, "compuesto por el dolor, la aflicción y en general los sentimientos de desesperación, congoja, desasosiego, temor, zozobra, etc., que invaden a la víctima directa o indirecta de un daño antijurídico, individual o colectivo". El deber del Estado colombiano es garantizar una vida digna, por ello la prestación humanitaria periódica para las víctimas del conflicto armado debería ser de manera vitalicia, para resarcir un poco el daño causado por su desprotección.
} 
sus propios recursos costear el valor del dictamen. No está demás decir que un porcentaje importante de las personas víctimas del conflicto armado en este país que han sufrido un hecho victimizante a causa de la violencia, son campesinos que no pueden pagar el costo de la valoración física, viven en zonas veredales de difícil acceso, donde no existe una Junta Regional, y alejadas de las cabeceras municipales, y además tienen dificultades para ubicarse en una ciudad más grande.

\section{Las dificultades de las víctimas de la violencia con pérdida de capacidad laboral para acceder al derecho de la PEI y PHP}

Por vía de acción de tutela, la Corte Constitucional realizó algunas precisiones, confirmadas por la sentencia C-767 de 2014, en el sentido de indicar que la prestación económica se encontraba vigente, fundamentándose en el principio de progresividad y no regresividad de los derechos sociales para las víctimas del conflicto armado interno de este país.

Las personas consideradas "inválidas" con ocasión del conflicto armado, son aquellas que sufrieron un hecho victimizante y que además el Estado los reconoció como "víctimas" dentro del Registro Único -RUV-. Adicionalmente, la persona debió ser calificada por la Junta Regional de Calificación de Invalidez del departamento de residencia. Para tener la condición de invalidez, el dictamen debe arrojar pérdida de capacidad laboral igual o superior al $50 \%$. La víctima deberá manifestar y probar que no tiene otra forma de pensionarse y que no devenga o recibe subsidio por un salario mínimo o superior a este. No es necesario haber cotizado al sistema pensional para solicitar la respectiva pensión en caso de que reúna los requisitos contemplados en el artículo 46 de la Ley 418 de 1997.

De plano, este pronunciamiento descarga la responsabilidad del Estado en cuanto a lo contencioso administrativo y lo traslada al Sistema General de Seguridad Social, que tiene su naturaleza en el aporte periódico según los requisitos exigidos por la ley para las pensiones $^{16}$.

\subsection{Pensiones especiales de invalidez (PEI) reconocidas}

Según los registros de la Red Nacional de Información de la UARIV (2017), por actos terroristas, atentados, combates y hostigamientos hay 96.278 personas víctimas, y por minas antipersonal, munición sin explotar y artefactos explosivos registran 11.140 víctimas.

En cuanto a las víctimas de la violencia por el conflicto armado en Colombia con posible pérdida de capacidad laboral igual o superior al $50 \%$, se evidencia que tan solo se encuentran reconocidas y activas en nómina 58 pensiones de invalidez para víctimas de la violencia (Colpensiones, 2017), dentro de las cuales hay dos pensiones de sobrevivientes. Están desglosadas de la siguiente manera:

Tabla 5. Casos de PEI reconocidos entre 2013-2017

\footnotetext{
${ }^{16}$ Para poder acceder al mismo, se debe cumplir con la cotización de 1300 semanas y haber cumplido si es hombre 62 años de edad y si se es mujer 57 años, asimismo, haber cotizado 50 semanas dentro de los últimos tres años, para tener acceso a la pensión de sobreviviente o de invalidez por origen común.
}

Pensión especial de invalidez y prestación humanitaria periódica para víctimas del conflicto armado en Colombia - Huertas Mendivelso, D., \& Pérez González, L. 


\begin{tabular}{|l|l|c|}
\hline AÑO & \multicolumn{1}{|c|}{ CONCEPTO } & RECONOCIDAS \\
\hline 2013 & Pensión Especial de Invalidez para Víctimas de la Violencia & 7 \\
\hline 2014 & Pensión Especial de Invalidez para Víctimas de la Violencia & 11 \\
\hline 2015 & Pensión Especial de Invalidez para Víctimas de la Violencia & 22 \\
\hline 2016 & Pensión Especial de Invalidez para Víctimas de la Violencia & 15 \\
\hline 2017 & Pensión Especial de Invalidez para Víctimas de la Violencia & 3 \\
\hline \multicolumn{2}{|c|}{ Total } & $\mathbf{5 8}$ \\
\hline
\end{tabular}

Fuente: Colpensiones (2017)

Estos 58 reconocimientos de pensiones a víctimas de la violencia por el conflicto armado, se efectuaron por orden de los jueces constitucionales vía sentencia de acción de tutela. En cuanto al tema pensional, debe resaltarse que la Corte Constitucional ha sido reiterativa en sostener que la acción de tutela es improcedente para obtener el reconocimiento de prestaciones económicas, pues, por su naturaleza excepcional y subsidiaria, esta no puede reemplazar las acciones ordinarias creadas por el legislador para resolver asuntos de naturaleza litigiosa.

No obstante, las personas víctimas de la violencia que han sufrido pérdida de capacidad laboral igual o superior al $50 \%$, se encuentran en debilidad manifiesta y en condiciones de vulnerabilidad altísima, por lo tanto requieren que sus derechos sean tutelados de manera inmediata, puesto que no existe otro mecanismo ordinario de defensa que resulte eficaz, o de serlo, es demorada la decisión, lo que llevaría a la configuración del perjuicio irremediable. La consecuencia del anterior proceder jurídico es el resultado del reconocimiento de la prestación económica a 58 personas durante los últimos cinco años, lo cual es un número insignificante frente al universo de víctimas que existe en este país y que pueden ser potenciales beneficiarios de la pensión especial de invalidez.

Por lo anterior, la Defensoría del Pueblo, en nombre de las 13 víctimas que representó y las 45 víctimas restantes, estimó la procedencia de sus respectivas acciones de tutela como mecanismo transitorio para amparar los derechos fundamentales a la vida digna, mínimo vital, dignidad humana en relación con el reconocimiento y pago de la pensión especial de invalidez para víctimas de la violencia contemplada en el artículo 46 de la Ley 418 de 1997.

Con relación a la acción de tutela, la sentencia de T- 469 de 2013 precisa, acerca del reconocimiento de la pensión especial de invalidez para víctimas de la violencia, lo siguiente:

[...] la acción de tutela para el reconocimiento y pago de la pensión por invalidez para víctimas de la violencia contemplados en la Ley 418 de 1997, es procedente siempre y cuando se acrediten los requisitos expuestos en este apartado, máxime cuando se trata de sujetos de especial protección constitucional, circunstancia que será objeto de estudio por parte de esta Sala. (Corte Constitucional, 2013)

\subsection{Reconocimiento de la prestación humanitaria periódica (PHP)}


Según información proporcionada por Colpensiones (2017), las estadísticas de las tutelas de víctimas de la violencia tienen fecha de corte hasta el 5 de abril de 2017, toda vez que el 6 de abril de 2017 entró en vigencia el Decreto 600 de 2017 que le quita la competencia a Colpensiones para entrar a reconocer pensión especial de invalidez y, en su lugar, se reconocerá la prestación humanitaria periódica para víctimas del conflicto armado, administrada por el Ministerio de Trabajo. Según datos de este Ministerio, para el 17 de octubre de 2017 se encontraban en estudio 220 solicitudes para el reconocimiento de la prestación humanitaria.

Respecto a los fallos de tutela contra Colpensiones, existe registro de 252 fallos de tutela, con corte al 5 de abril de 2017, donde se ha discutido el trámite de la prestación humanitaria para víctimas de la violencia, en los cuales los jueces han tomado las siguientes decisiones: 100 fallos a favor de Colpensiones, 40 fallos ordenan reconocer la prestación económica para víctimas de la violencia, cuatro fallos ordenan realizar el proceso de calificación de pérdida de capacidad laboral de las personas víctimas de la violencia, y 108 fallos a favor de la Administradora Colombiana de Pensiones -Colpensiones-. La siguiente figura ilustra lo expresado:

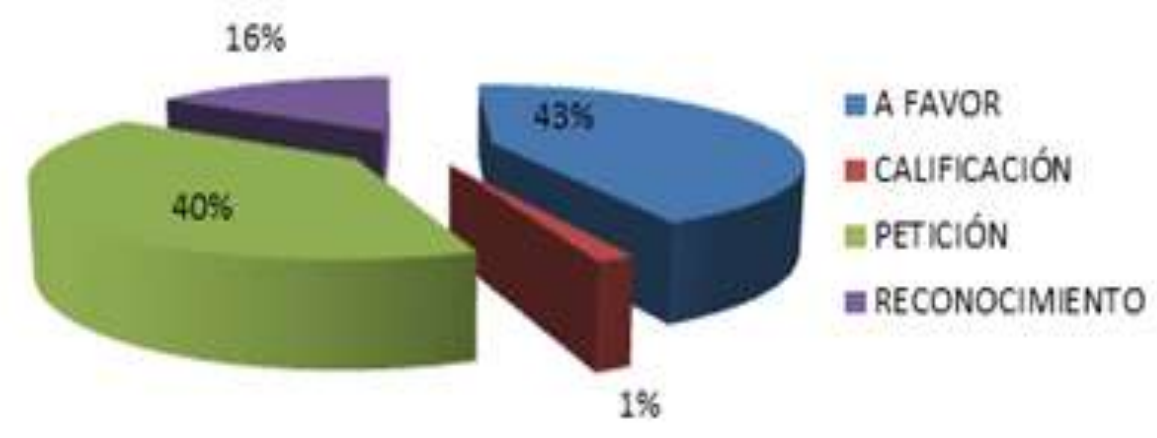

Figura 1. Distribución de los fallos judiciales relacionados con la PHP Fuente: Colpensiones (2017)

Además de las principales barreras que tuvieron en su momento las víctimas para acceder a la pensión especial de invalidez, en la actualidad para ser beneficiarios de la prestación humanitaria periódica con el Decreto 600 de 2017, deben enfrentar las siguientes vicisitudes:

a) Presencia estatal: hay regiones y cientos de poblaciones en la geografía nacional, donde la falta de presencia e inoperancia del Estado es absoluta, este no existe o es muy débil. Lo peor es que en estas zonas apartadas la pobreza es extrema, el abandono por parte de las instituciones públicas y defensoras de derechos humanos es total. No solamente hace falta la presencia del Estado a través de sus instituciones o de fuerza pública, sino que hay debilidad manifiesta en aspectos como educación, salud, servicios públicos, vías de acceso y otros factores que son necesarios para garantizar las condiciones básicas y dignas de toda persona. 
b) Desconocimiento de derechos: las víctimas de la violencia que han tenido pérdida de capacidad laboral igual o superior al $50 \%$, no saben cuáles son sus derechos, los mismos que deben ser protegidos por el Estado, no saben dónde exigir el reconocimiento de estos, ni a dónde acudir para recibir prestación humanitaria mínima, constituida en atención básica para aminorar sus situaciones de desprotección y abandono. A pesar de que la sentencia T-469 de 2013 ordenó a Colpensiones que debía informar a los ciudadanos víctimas de la violencia que solicitaran el reconocimiento y el pago de la pensión especial de invalidez, no se evidenció un trabajo o estrategia de difusión e información por parte de la Administradora, ni de ninguna otra Entidad estatal para que los potenciales beneficiarios solicitaran la pensión especial. Este aspecto es de suma importancia, si se considera que un número significativo de víctimas son campesinos que residen en zonas rurales remotas y de difícil acceso.

c) Invisibilización de la población víctima: de las 96.278 personas víctimas de actos terroristas, atentados, combates y hostigamientos y 11.140 víctimas de minas antipersonal, munición sin explotar y artefactos, solamente 58 personas fueron pensionados de invalidez por Colpensiones (pensión que ya está cancelando el Ministerio del Trabajo). Se encuentran 220 casos en estudio ante el Ministerio de Trabajo para reconocimiento de la prestación humanitaria periódica por ser víctimas del conflicto armado interno. Con las anteriores cifras se evidencia de manera clara la invisibilización que tienen las víctimas de la violencia por el conflicto armado colombiano.

d) Falta de conocimiento de la norma: ha habido más de seis proyectos de ley que han aprobado, derogado y plasmado instrucciones para reconocimiento de pago de pensión especial de invalidez para víctimas de la violencia y más de seis sentencias emanadas por las altas cortes indicando los principios y declarando la vigencia de la pensión especial de invalidez; asimismo, tres conceptos por parte de Colpensiones.

e) Falta de requisitos mínimos y documentación: hay víctimas de la violencia que ni siquiera han declaro su condición para ser registradas en el RUV, a lo cual se agrega que en muchos casos las víctimas no alcanzan a reunir algunos de los siete requisitos establecidos en el Decreto 600 de 2017 para prestación humanitaria periódica.

f) Condición económica: la mayoría de las víctimas de la violencia no cuentan con dinero para enfrentar sus necesidades diarias. También es requisito no estar recibiendo ingresos por ningún concepto: ni subsidio, auxilio o cualquier otro beneficio económico. Se debe considerar que las víctimas no pueden trabajar porque son incapaces de ejercer alguna función que implique fuerza u otra destreza física. A esto se suma que muchas víctimas potenciales beneficiarias viven en veredas y zonas rurales lejos de la capital del departamento. Sin embargo, para poder acceder como posibles beneficiarios de la prestación humanitaria periódica para las víctimas del conflicto armado, estas deben pagar con sus propios recursos el dictamen de pérdida de capacidad laboral, según el Decreto 1072 de 26 de mayo de 2015. Esta condición de precariedad económica los ha llevado a la pobreza extrema, 
profundizado la indigencia y a depender de la caridad de los familiares y vecinos para subsistir diariamente.

\section{Conclusiones}

La indagación sobre el proceso para garantizar el derecho a una pensión especial de invalidez para víctimas de la violencia o prestación humanitaria periódica, permite inferir:

No hay certeza en el número de víctimas de la violencia del conflicto armado afectadas en su integridad personal en un $50 \%$ o más de pérdida de capacidad laboral. Los registros existentes por parte de la RNI-UARIV reportan registros agregados de varios hechos victimizantes que demandan un mayor esfuerzo e información para discriminar tales resultados, además tienen derecho a la pensión aquellas personas que por causa del conflicto armado tienen discapacidad mental. En este sentido, resulta difícil cuantificar la población víctima objeto de reparación potencial con pensión especial de invalidez o prestación humanitaria periódica para víctimas del conflicto armado.

Desde la promulgación de la Ley 418 de 1997, que reglamenta y ordena el pago de una pensión especial de invalidez para víctimas de la violencia, hasta este año 2017, se han reconocido solamente 58 víctimas. Este resultado se alcanzó en el lapso de 2015-2017. Para lograrlo, las víctimas debieron recurrir a mecanismos legales para exigir el reconocimiento de dicho derecho (como la tutela) o a través de la intervención del Ministerio Público como la Defensoría del Pueblo.

Estos resultados evidencian una ineficacia y lentitud institucional que conspira perversamente contra los derechos de las víctimas afectadas en su integridad personal por la violencia del conflicto armado. Asimismo, contribuye a revictimizarlas en su condición de discapacitadas, ya que al no poder generar ingresos para garantizar la sostenibilidad de su familia y la suya misma, las condena a la pobreza extrema o la indigencia.

Como se observó, no existen criterios uniformes en la administración de justicia, ni ha sido posible que se emita un marco jurisprudencial que ampare los derechos de las víctimas del conflicto armado que han quedado en condición de discapacidad. Lo anterior ha llevado a que los jueces se pronuncien frente a reclamaciones y demandas de derechos similares en forma discrecional y ampliamente disímil, sin tomar en cuenta las circunstancias especiales de desprotección de estas personas y en muchos casos favoreciendo los planteamientos de defensa jurídica interpuestos por las instituciones responsables de dar respuesta y garantizar los derechos de las víctimas, como es el caso de Colpensiones.

\section{Referencias}

Carrillo, B. F. (2016). Análisis jurídico de la pensión especial de invalidez para las víctimas del conflicto armado en Colombia. San José de Cúcuta, Norte de Santander, Colombia: Universidad Libre. 
Colpensiones (2017). Pensión especial de invalidez para víctimas de la violencia. Bogotá: Dirección de Procesos Judiciales y Gerencia de Planeación de Colpensiones.

Congreso de la República de Colombia. (1993). Ley 100 de 23 diciembre de 1993, por la cual se crea el sistema de seguridad social integral y se dictan otras disposiciones. Diario Oficial, (41.148).

Congreso de la República de Colombia. (1993). Ley 104 de 30 de diciembre de 1993, por la cual se consagran unos instrumentos para la búsqueda de la convivencia, la eficacia de la justicia y se dictan otras disposiciones. Diario Oficial, (41.158).

Congreso de la República de Colombia. (1997). Ley 418 del 26 de diciembre de 1997, por la cual se consagran unos instrumentos para la búsqueda de la convivencia, la eficacia de la justicia y se dictan otras disposiciones. Diario Oficial, (43201).

Congreso de la República de Colombia. (1999). Ley 548 del 23 de diciembre de 1999, por medio de la cual se prorroga la vigencia de la Ley 418 del 26 de diciembre de 1997 y se dictan otras disposiciones. Diario Oficial, (43.827).

Congreso de la República de Colombia. (2003). Ley 797 de 29 de enero de 2003, por la cual se reforman algunas disposiciones del sistema general de pensiones previsto en la Ley 100 de 1993 y se adoptan disposiciones sobre los regímenes pensionales exceptuados y especiales. Diario Oficial, (45.079).

Congreso de la República de Colombia. (2006). Ley 1106 del 22 de diciembre de 2006, por medio de la cual se prorroga la vigencia de la Ley 418 de 1997 prorrogada y modificada por las Leyes 548 de 1999 y 782 de 2002 y se modifican algunas de sus disposiciones. Diario Oficial, (46490).

Congreso de la República de Colombia. (2011). Ley 1448 del 1 de junio de 2011, por la cual se dictan medidas de atención, asistencia y reparación integral a las víctimas del conflicto armado interno y se dictan otras disposiciones. Diario Oficial, (48096).

Consejo de Estado. Sala de lo Contencioso Administrativo. Sección Tercera. Sentencia 2000-00340 de agosto 28 de 2014. Magistrado Ponente: Dr. Danilo Rojas Betacourth. Exp. 25000232600020000034001 (28832).

Corte Constitucional de Colombia (1992). Sentencia T-491 de agosto 13 de 1992. En, http://www.corteconstitucional.gov.co/relatoria/1992/T-491-92.htm

Corte Constitucional de Colombia. (2004). Sentencia T-025 de 2004. Bogotá: Imprenta Nacional.

Corte Constitucional de Colombia. (2013). Sentencia T-469 de 2013. Bogotá: Imprenta Nacional 
Corte Constituional de Colombia. (2014). Sentencia C-767 de 2014. Bogotá: Imprenta Nacional.

Corte Constitucional de Colombia. (2014). Sentencia T-921 de 2014. Bogotá: Imprenta Nacional.

Corte Constitucional de Colombia. (2015). Sentencia T-032 de 2015. Bogotá: Imprenta Nacional.

Corte Constitucional de Colombia. (2015). Auto 290 de 2015.

Corte Constitucional de Colombia. (2015). Sentencia T-074 de 2015. Bogotá: Imprenta Nacional.

Corte Constitucional de Colombia. (2016). Sentencia Unificada N. ${ }^{o} 587$ de 2016. Bogotá: Imprenta Nacional.

Defensoría del Pueblo. (2015). Acción de tutela en representación de víctimas del conflicto armado con pérdida de capacidad laboral igual o superior al $50 \%$ para el conocimiento de la pensión especial de invalidez contra Colpensiones. Bogotá: 10 de noviembre de 2015.

Fundación Ideas para la Paz. (2007) Las dos caras de la reparación: ¿vía judicial o vía administrativa? En, http://www.ideaspaz.org/publications/posts/174

Giroux, S. \& Tremblay, G. (2004). Metodología de las ciencias humanas. La investigación en acción. México: Fondo de Cultura Económica.

Grupo de Memoria Histórica. (2013). Basta ya. Colombia: Memorias de guerra y dignidad. Bogotá: Imprenta Nacional.

Merchán, C. A. (2002). Pensiones: conceptos y esquemas de financiación. DNP Archivos de Economía, 4.

Ministerio del Trabajo (2016, junio). Juntas de Calificación de Invalidez. Recuperado de http://fondoriesgoslaborales.gov.co/seccion/juntas-calificacion-invalidez.html

Ministerio del Trabajo. (2017, 6 de abril). Decreto 600 del 2017, por el cual se adiciona al título 9 de la parte 2 del libro 2 del Decreto 1072 de 2015 un capítulo $5^{\circ}$, para reglamentar la prestación humanitaria periódica para las víctimas del conflicto armado, de que trata el artículo 46 de la Ley 418 de 1997, y su fuente de financiación. Diario Oficial, (50.198).

UARIV (2017). Unidad para la Atención y Reparación Integral a las Víctimas https://www.unidadvictimas.gov.co/es/la-unidad/resena-de-la-unidad/126

Pensión especial de invalidez y prestación humanitaria periódica para víctimas del conflicto armado en Colombia - Huertas Mendivelso, D., \& Pérez González, L. 
Verri, P. (1999). Diccionario de derecho internacional de los conflictos armados. Bogotá: Comité Internacional de la Cruz Roja y Tercer Mundo Editores.

Waldmann, P. (2007). Guerra civil, terrorismo y anomia social. El caso colombiano en un contexto globalizado. Bogotá: Norma.

\section{Derechos de autor}

Los derechos de autor de este artículo son retenidos por los autores, con los derechos de primera publicación otorgados a la revista. Este es un artículo de acceso abierto distribuido bajo los términos y condiciones de la licencia Creative Commons: Reconocimiento-NoComercial-CompartirIgual 4.0 Internacional 